Cite as: Roncero, C., Daigre, C., Gonzalvo, B., Valero, S., Castells, X., Grau-López, L., ... Casas, M. (2013). Risk factors for cocaine-induced psychosis in cocaine-dependent patients. European Psychiatry, 28(3), 141-146. https://doi.org/10.1016/j.eurpsy.2011.06.012

\title{
Risk factors for cocaine-induced psychosis in cocaine-dependent patients
}

Carlos Roncero" ${ }^{1,3}$, Constanza Daigre', Begoña Gonzalvo', Sergi Valero' ${ }^{2,3}$, Xavier Castells $^{2,4}$ Lara Grau-López ${ }^{1}$, Francisco Jose Eiroa-Orosa ${ }^{2,3}$ and Miguel Casas ${ }^{2,3}$.

1.- Outpatient Drug Unit. University Hospital Vall d'Hebrón, Universitat Autónoma de Barcelona.

2.- Psychiatry Department. Vall d'Hebrón Hospital. Universitat Autónoma de Barcelona.

3.- Department of Psychiatry and Forensic Medicine, Universitat Autònoma de Barcelona, Barcelona, Catalonia, Spain.

4.- Unit of Clinical Pharmacology, Department of Medical Sciences, Universitat de Girona, Girona, Catalonia, Spain.

\section{Corresponding author:}

Carlos Roncero Alonso

Servicio de Psiquiatría. Hospital Universitario Vall Hebron.

Passeig de la Vall d'Hebron, 119-129, 08035 Barcelona, Spain.

croncero@vhebron.net

+34934893880 


\title{
Risk Factors for cocaine-induced psychosis in cocaine dependent patients
}

\begin{abstract}
Cocaine consumption can induce transient psychotic symptoms, expressed as paranoia or hallucinations. Cocaine induced psychosis (CIP) is common but not developed in all cases. This is the first European study on the relationship between CIP, consumption pattern variables and personality disorders. We evaluated 173 cocaine-dependent patients over 18 years; mostly males, whose average age was 33.6 years ( $\mathrm{SD}=7.8$ ). Patients attending an outpatient addictions department were enrolled in the study and subsequently systematically evaluated using, SCID I and SCID II interviews for comorbid disorders, a clinical interview for psychotic symptoms and EuropASI for severity of addiction. A high proportion of cocaine dependent patients reported psychotic symptoms under the influence of cocaine $(53.8 \%)$, the most frequently reported being paranoid beliefs and suspiciousness (43.9\%). A logistic regression analysis was performed, finding that a model consisting of amount of cocaine consumption, presence of an antisocial personality disorder and cannabis dependence history had $66.2 \%$ sensitivity $75.8 \%$ specificity predicting the presence of CIP. In our conclusions we discuss the relevance of evaluating CIP in all cocaine dependentpatients, and particularly in those fulfilling the clinical profile derived from our results. These findings could be useful for a clinical approach to the risks of psychotic states in cocaine-dependent patients.
\end{abstract}

Key Words: Cocaine, psychosis, Cocaine induced psychosis risk factors, antisocial personality disorder, cannabis dependence. 
Cocaine consumption and demands for treatment have increased in Europe in recent years. On average, in Europe 14 million Europeans have used it at least once in their life, (4.1\% of adults aged 15-64 years) and 4 million Europeans have used the drug in the last year $(1.3 \%)$, being Spain the leading European country in the consumption of cocaine (1). The US National Comorbidity Survey found that $3.8 \%$ of the general population has a substance use disorder, and $65 \%$ of drug dependent individuals develop at least one mental disorder throughout their lifetime (2, 3). Chronic consumption of cocaine can induce transient psychotic symptoms, expressed as paranoia or hallucinations. The term cocaine induced psychosis (CIP) has been used to describe this syndrome. These symptoms disappear typically with abstinence (4-8).

Associating these symptoms with a DSM-IV diagnostic category is a complex process. CIP symptoms can appear with cocaine intoxication and they can also be present in psychotic disorders induced by cocaine. These diagnostic criteria are controversial and have been the subject of some criticism (9). Assessment of psychotic symptoms induced or exacerbated by cocaine in patients with chronic psychotic disorders such as schizophrenia or bipolar disorder is difficult because such patients often lack insight into their psychotic symptoms, whether or not they are cocaine-related. In contrast, cocaine users without chronic psychotic disorders, but who report CIP, almost always have retrospective insight into the distorted nature of their experiences during cocaine intoxication, even though they often lack such insight while intoxicated.

Besides the risks associated with CIP symptoms, some studies have observed that drug dependent-individuals with cocaine induced paranoia are at higher risk of developing a psychotic disorder $(4,10)$.

CIP prevalence is not exactly known; different studies have reported prevalences between $48 \%$ and $88 \%$ (11-13). The wide range of prevalences found are probably due to the variability and bias in the samples studied, the different study designs, instruments used for assessment, and administration routes used.

As for the clinical factors that moderate the appearance of CIP, several factors have been found that increase the possibility of a CIP. Several researches agree with the idea that the amount of cocaine consumed both in laboratory and clinical studies $(8,14-17)$ and early-onset of cocaine use $(6,12,14)$ are positively related to CIP. It has also been reported that the early-onset of cocaine dependence, or in vulnerable periods of brain development, may lead to increase the severity of CIP $(14,18)$. However, it has been 
found that the number of years of cocaine use does not correlate with cocaine-induced psychosis (19). It has also been established that different routes of administration from the nasal airway like smoking (15) or intravenous use (17) may increase the risk of CIP. Comorbidity with other substance use disorders, such as cannabis use seems to play a mediating role for developing psychotic symptoms. Tang et al. observed a statistically significant difference in the frequency of CIP in cocaine dependent individuals based on cannabis dependence, but this difference did not remain statistically significant after adjusting for age and sex (7). Kalayasiri et al. recently found that adolescent-onset of cannabis use increases the risk of CIP in cocaine dependent individuals (12).

CIP can be linked to hostile behaviours and antisocial personality disorder (ASPD). A pattern in which the stimulants generate hostility through psychotic symptoms has been suggested. This contributes to a perception of the environment as a hostile and threatening place, as well as through increasing impulsivity, thus CIP can trigger hostile behaviours $(7,20)$.

Although the assessment of traits and personality disorders during heavy drug use is complex and there is debate about its stability $(21,22)$, comorbid Axis II disorders are especially prevalent in cocaine users. Several studies found prevalences of personality disorders ranging from 30 to $77 \%$ in inpatient or outpatient samples (10), being antisocial and borderline personality disorders, the most prevalent (23). Kranzler et al. compared the frequency of CIP in patients with and without personality disorders but did not find significant differences (10). However, it is possible that antisocial personality traits are related with CIP. Recently, Tang identified that cocaine-dependent patients who experienced CIP tend to present a comorbid ASPD more frequently (7). Despite this, the relationship between personality disorders and psychotic symptoms induced by cocaine, are clearly not sufficiently analysed.

This study examined the relationship between CIP and substance consumption variables and personality disorders, and attempted to identify risk factors for CIP. Although other studies have been published on this topic, this is the first to study both substance consumption and personality disorders simultaneously in a European clinical sample. 


\section{Subjects and Methods}

\subsection{Procedure}

We performed a cross-sectional, observational study. The participants were patients of the Psychiatric Department of the Vall d'Hebron Hospital (Barcelona, Spain). Specifically, they were cocaine-dependent patients treated in a Substance Use Disorders Unit, who began treatment between January 2006 and December 2008. This study is part of a more extensive research on the comorbidity in cocaine dependence.

Inclusion criteria were: age over 18, cocaine dependence according to DSM-IV criteria, and signing the informed consent prior to participation. Exclusion criteria were: psychotic disorder or bipolar type I disorder, intoxication at baseline examination, severe somatic disease at baseline examination and low language proficiency. We excluded psychotic and bipolar patients in order to avoid the risk of not being able to distinguish primary and secondary symptomatology. However, its known that CIP can be measured in psychotic patients (24) The research was approved by the Ethics Committee of the Vall d'Hebron Hospital. Patients did not receive any financial compensation for taking part in this study.

The evaluation process consisted of three interview sessions conducted by trained psychiatrists and psychologists. The psychiatrists performed the evaluation of substance use disorders, CIP and variables related with cocaine consumption; this interview corresponded to the first medical visit. Psychologists measured severity of substance use disorder and personality disorders in the second and third interviews.

\subsection{Participants}

From a total of 238 patients who contacted our unit, 173 finally took part in the study. The flow chart of the study is presented in Figure 1. 


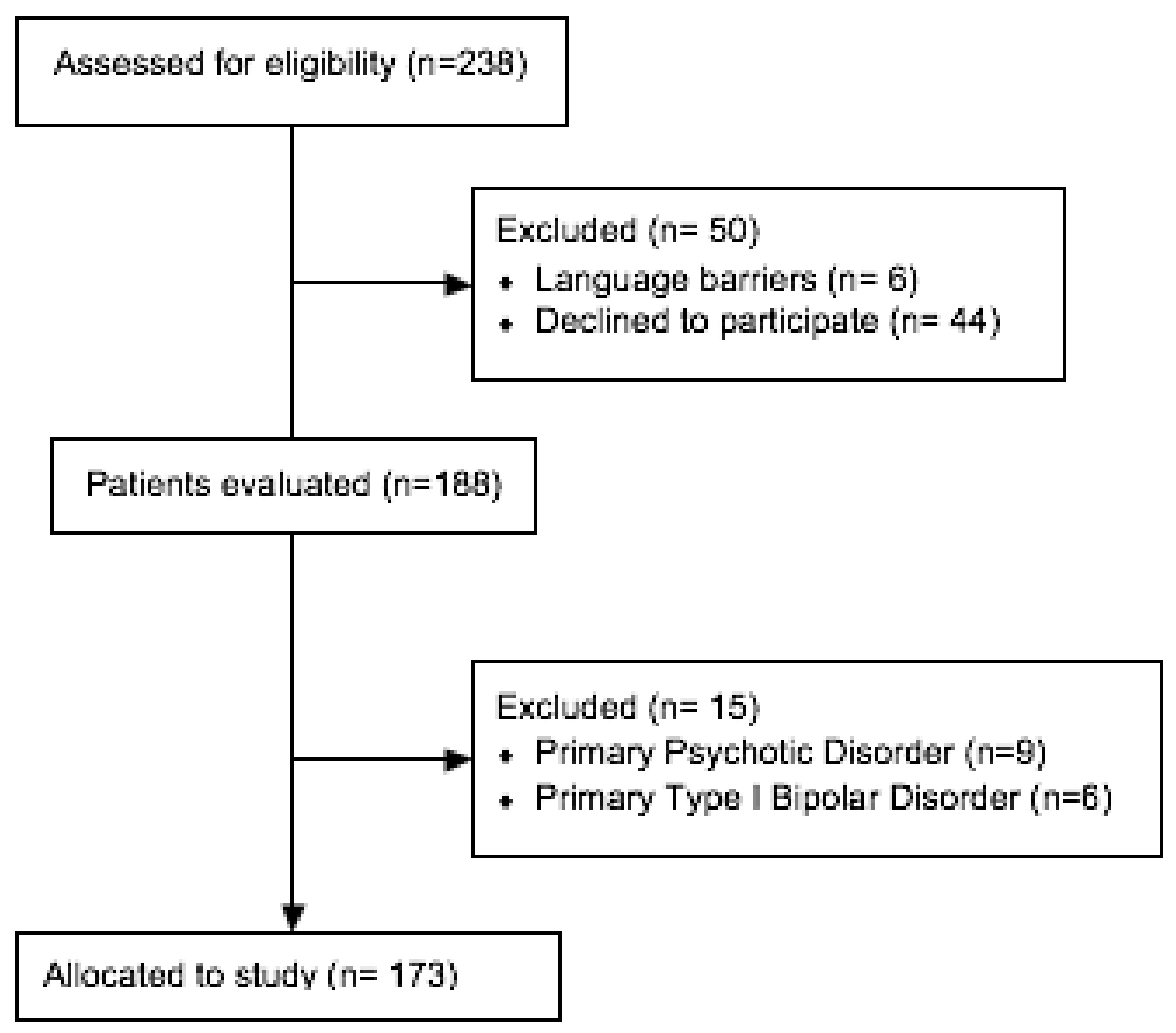

\subsection{Data collection}

2.3.1. Cocaine Induced Psychosis (CIP). Trained psychiatrists systematically conducted a structured interview in which the conclusions from the sensoperceptive examinations were summarized. The patients were asked about the psychotic symptoms they had experienced under the influence of cocaine throughout their life. This examination included four questions about paranoid beliefs, auditory, visual and kinetic hallucinations. The questions were: 1) Have you ever heard, or thought you heard, something that wasn't really there? Did it happen while you were under the effects of cocaine? 2) Have you ever seen, or thought you saw something, that wasn't actually there? Did it happen under the effects of cocaine? 3) Have you ever felt anything unusual on your body or on your skin? Did it happen while you were under the effects of cocaine? 4) Have you believed that people were spying on you, or that someone was plotting against you, or trying to hurt you? Did it happen while you were under the effects of cocaine? Patients were considered CIP positive by the psychiatrist if they were marked positively in any of the above questions. 
2.3.2. Severity of substance use disorder. The Spanish version of the European Addiction Severity Index (EuropASI) was used (25). This is a face-to-face structured interview which measures several domains: general medical information, alcohol and drug use, employment and support, family and social relationships, legal status and psychiatric status. The EuropASI is an adaptation of the fifth version of the Addiction Severity Index $(26,27)$. It is one of the most widely used assessment and diagnostic tools in Europe.

2.3.3. Variables related with cocaine consumption. Amount of cocaine consumed per week, years of cocaine dependence and main cocaine route of administration at the beginning of the treatment were systematically registered.

2.3.4. Substance Use Disorders. The Structured Clinical Interview for DSM IV Axis I disorders (SCID I) was used in order to identify substance use disorders (28). This tool is widely used and it has shown good psychometric properties (29).

2.3.5. Personality Disorders. The Structured Clinical Interview for DSM IV Axis II Personality Disorders (SCID II) was used to evaluate this topic. This tool has shown adequate reliability and usefulness in providing fine discriminations between Axis II disorders (30). The Spanish translation has an overall kappa of 0.85(31).

\subsection{Data Analysis}

Data analysis was performed in three steps: descriptive, bivariate and multivariate analyses. The first step includes the description of all variables in terms of percentages, means and standard deviations. These variables were clustered in four groups: a) demographic variables, including gender, age, educational level and nationality, b) cocaine consumption pattern, including weekly amount of cocaine consumed, years of cocaine dependence and main cocaine route of administration c) lifetime substance use disorders, including cannabis, opioids, benzodiazepines, alcohol and tobacco dependence, and d) personality disorders (Antisocial Personality Disorder and Borderline Personality Disorder). The second step consisted in analyzing bivariate associations between each variable described above and CIP. The Kolmogorov-Smirnov test was used as a measure of normality. In this context, Mann-Whitney U and Chisquare tests were performed. In order to reduce the presence of some false positive effects, different Bonferroni corrections for multiple tests were performed. The 
magnitude of each correction was a function of the number of variables in each of the four clusters of variables described above. Consequently, demographic variables were only considered significant with a $P$ value less than $.013(.05 / 4)$. Variables included in the cocaine consumption pattern had a reference $P$ value of .017 (amount of cocaine consumed per week, route of cocaine consumption, and years of cocaine dependence). In the case of the variables included in the substance dependences (cannabis, opioids, benzodiazepines, alcohol and tobacco) cluster the p value was .01 (.05/5) and in the case of personality disorders the $P$ value was $.025(.05 / 2)$. Only the variables that exceeded the respective $P$ values participated in the second analysis. In this step these variables were used in a multivariate logistic regression analysis as predictors, using backward conditional entry in order to perform an exploratory analysis including CIP as a dependent variable. In order to provide information on the adjustment of the resulting model, sensitivity (capacity to detect CIP subjects) and specificity (capacity to detect non CIP subjects) parameters were reported. Subsequently, in order to identify a symptomatic pattern, relations of psychotic symptoms with independent variables included in the model were analysed using bivariate statistics. All statistical hypotheses were two-tailed. SPSS, version 18.0 for Windows was used for all analyses.

\section{Results}

\subsection{Descriptive information}

A shown in Table 1, most of the participants were young Spanish males and with primary school studies. The European Severity Index scores showed that employment status, family relationship and psychiatric status were the most affected domains.

Table 1: Demographics, substance use disorders and EuropASI scores of the sample $(n=173)$

\begin{tabular}{ccccccc}
\hline & $\begin{array}{c}\text { All subjects } \\
(\mathbf{n = 1 7 3})\end{array}$ & $\begin{array}{c}\text { CIP (-) } \\
(\mathbf{n = 8 0})\end{array}$ & $\begin{array}{c}\mathbf{C I P}(+) \\
(\mathbf{n = 9 3})\end{array}$ & $\chi^{2}$ & $\boldsymbol{Z}$ & $\boldsymbol{p}$ \\
Males & $80.3 \%$ & $73.8 \%$ & $86.02 \%$ & 4.101 & & .043 \\
Mean age & 33.6 & 32.68 & 34.63 & & -1.478 & .139 \\
Completed primary & $62.6 \%$ & $61.1 \%$ & $63.9 \%$ & .147 & & .701 \\
school studies or less & $91.1 \%$ & $93.7 \%$ & $88.9 \%$ & 1.189 & & .275 \\
Spanish Citizenship & & & & & & \\
\hline
\end{tabular}




\begin{tabular}{cl}
\hline Mean EuropASI & \\
Medical status & Mean $.20(\mathrm{SD}=.27)$ \\
Employment status & Mean $.50(\mathrm{SD}=.34)$ \\
Alcohol use & Mean $.25(\mathrm{SD}=.19)$ \\
Substance use & Mean $.20(\mathrm{SD}=.22)$ \\
Legal status & Mean $.13(\mathrm{SD}=.23)$ \\
Family relationships & Mean $.36(\mathrm{SD}=.28)$ \\
Psychiatric status & Mean $.35(\mathrm{SD}=.25)$ \\
\hline
\end{tabular}

\subsubsection{Cocaine Induced Psychosis symptoms}

Psychotic symptoms were found under the influence of cocaine in $53.8 \%$ of cocaine dependent-patients interviewed. The most frequently reported psychotic symptoms were paranoid beliefs and suspiciousness (43.9\%). Auditory hallucinations were reported by $30.9 \%$, visual hallucinations by $26.1 \%$, and kinaesthetic hallucinations by $10.3 \%$.

\subsection{Bivariate analyses}

\subsubsection{Consumption pattern and CIP}

Patients with CIP consumed larger amounts of cocaine per week in the month before they began treatment. They reported a mean of 12 grams per week $(\mathrm{SD}=11.24)$ and patients without CIP reported 6 grams per week $(\mathrm{SD}=9.61$; difference between groups $z$ $=3.44, \mathrm{p}<.0001)$.

With regards to cocaine route of administration, intranasal as the main administration route $(73.8 \%$ in the whole sample) was significantly more frequent in patients without CIP (84\% vs. $\left.65.6 \%, \chi^{2}=7.278, P=.007\right)$. Among patients with CIP, $21.2 \%$ consumed intravenously and $12.8 \%$ smoked the cocaine. With respect to the years of cocaine dependence, we identified homogeneity between groups with and without CIP (9.5 and 8.76 years respectively, $z=1.41, P=.156$ ). From this group, amounts of cocaine consumed per week and the route of administration remained statistically significant after Bonferroni correction.

\subsubsection{Substance Use Disorders}

As can be seen in Table 2, we found that cocaine dependent patients with CIP tend to be cannabis and tobacco dependent throughout their lives more often than patients without CIP. From this group, only lifetime cannabis dependence remains statistically significant after Bonferroni correction. 
Table 2: Personality Disorders and Substance use disorders in lifetime according to Cocaine Induced Psychosis

\begin{tabular}{lccccc}
\hline & $\begin{array}{c}\text { All subjects } \\
(\mathbf{n = 1 7 3})\end{array}$ & $\begin{array}{c}\text { CIP (-) } \\
(\mathbf{n = 8 0})\end{array}$ & $\begin{array}{c}\mathbf{C I P}(+) \\
(\mathbf{n}=\mathbf{9 3})\end{array}$ & $\chi^{2}$ & $\boldsymbol{p}$ \\
\hline Paranoid personality disorder & $4.1 \%$ & $0 \%$ & $8.6 \%$ & & \\
Schizoid personality disorder & $1.6 \%$ & $(3.1 \%)$ & $0 \%$ & & \\
Schizotypal personality disorder & $0 \%$ & $0 \%$ & $0 \%$ & & \\
Antisocial personality disorder & $16.9 \%$ & $10.8 \%$ & $26.2 \%$ & 5.471 & .019 \\
Borderline personality disorder & $18.5 \%$ & $10.8 \%$ & $24.6 \%$ & 4.279 & .039 \\
Histrionic personality disorder & $1.6 \%$ & $1.5 \%$ & $1.7 \%$ & & \\
Narcissistic personality disorder & $1.6 \%$ & $0 \%$ & $3.4 \%$ & & \\
Avoidant personality disorder & $2.4 \%$ & $1.5 \%$ & $3.4 \%$ & & \\
Dependent personality disorder & $2.4 \%$ & $0 \%$ & $4.6 \%$ & & \\
Obsessive-compulsive personality disorder & $.8 \%$ & $1.5 \%$ & $0 \%$ & & \\
Passive-aggressive behaviour & $1.6 \%$ & $0 \%$ & $3.4 \%$ & & \\
\hline & & & & & \\
Cannabis dependence & $35.2 \%$ & $23.4 \%$ & $45.5 \%$ & 9.278 & .002 \\
Opioid dependence & $22.7 \%$ & $21 \%$ & $24.2 \%$ & .002 & .960 \\
Benzodiazepine dependence & $11.8 \%$ & $11.5 \%$ & $12.1 \%$ & .035 & .851 \\
Alcohol dependence & $22.8 \%$ & $23 \%$ & $22.7 \%$ & .469 & .493 \\
Tobacco dependence & $84.4 \%$ & $77.5 \%$ & $89.9 \%$ & 4.623 & .032 \\
\hline
\end{tabular}

CIP (-): Patients without Cocaine Induced Psychosis.

CIP (+): Patients with Cocaine Induced Psychosis.

\subsubsection{Axis II}

As shown in Table 2, Borderline Personality Disorder (BPD) and ASPD were the most prevalent. Only these showed a rate that allowed their statistical significance to be tested. When comparing patients with and without CIP, we found that both BPD and ASPD are associated with psychotic symptoms in consumption contexts. From this group, only antisocial personality disorder remains statistically significant after Bonferroni correction.

\subsection{Multivariate analysis}

A backward conditional logistic regression analysis was carried out in order to analyze all variables from the previous bivariate analysis that remained statistically significant after Bonferroni correction. These variables were: cocaine grams/week, antisocial personality disorder, lifetime cannabis dependence, and route of administration (we grouped this variable in intranasal versus the rest of routes due to the fact that 
absorption of smoked cocaine and iv injection is rapid in comparison with intranasal $(32,33)$. The two resulting models differed only in the route of administration as a predictor. Both models were statistically significant (First $\chi^{2}=21.501, \mathrm{p}<.001$, second $\left.\chi^{2}=19.122, \mathrm{p}<.001\right)$ but no the step between them $\left(\chi^{2}=2.379, \mathrm{p}=.123\right)$, being the $\mathrm{R}$ squared higher for the first model (Cox=.156 vs. .140). This can happen due to the existence of a strong correlation among independent variables. Being all statistically associated, we decided to take all in account for the analysis due to its conceptual independence, but using conditional entry with the objective of discarding variables with low explicative capacity.

Amount of cocaine and ASPD were significant in both models. Lifetime cannabis dependence had only a statistical tendency using a standard cut point of .05 (the standard criteria of non-inclusion in conditional models is .1). However, according to the literature, cannabis dependence could contribute to psychotic symptomatology (12, $34,35)$. Furthermore, we tested a model without cannabis dependence obtaining lower sensibility and specificity. Therefore, we maintained this variable in the model. Patients included in the CIP group with an ASPD were found to have a more symptomatology (paranoid beliefs and suspiciousness $\chi^{2}=5.917, \mathrm{p}=.015$; auditory hallucinations $\chi^{2}=8.175, \quad \mathrm{p}=.017 ;$ visual hallucinations $\chi^{2}=12.908, \mathrm{p}=.002$ and kinaesthetic hallucinations $\left.\chi^{2}=6.759, \mathrm{p}=.034\right)$. In the same way, patients with history of cannabis dependence and CIP showed higher levels of symptomatology (paranoid beliefs and suspiciousness $\chi^{2}=9.167, \mathrm{p}=.002$; auditory hallucinations $\chi^{2}=5.961, \mathrm{p}=.051$; visual hallucinations $\chi^{2}=7.071, \mathrm{p}=.029$ and kinaesthetic hallucinations $\chi^{2}=6.942, \mathrm{p}=.031$ ).

\section{Discussion}

The present research examines the relationship of cocaine-induced psychosis with consumption patterns and personality disorders in cocaine dependent patients. The results shown that CIP is very common in cocaine-dependent patients who seek treatment, and particularly in patients who consume higher doses of cocaine, diagnosed with antisocial personality disorder and cannabis dependence throughout their lives.

Although our objective was not to identify the prevalence of CIP, these results show a frequency of several psychotic symptoms reported by cocaine-dependent patients in a general hospital sample. Although these symptoms were communicated by more than 
half of the patients seeking treatment, our study reports a relatively low rate of CIP probably because we failed to take in account behavioural symptoms. However, it has been hypothesized that the appearance of CIP in the first contacts with cocaine is associated with a lower risk of developing cocaine addiction (36). The most often reported psychotic symptoms were paranoid beliefs and suspiciousness. These results are consistent with results from previous investigations, which found frequencies between $48 \%$ and $88 \%(4,6,7,11,18)$.

We also found that the amount of cocaine consumed at the beginning of treatment is a risk factor for CIP, consistently with data from retrospective reports and laboratory studies $(8,14,16,17)$. It has been reported that the substance use disorder severity is associated with the prevalence of psychotic symptoms, and that the prevalence of CIP is higher in dependent individuals than in abusers of cocaine (11), and in the most severely dependent patients $(11,12)$. One explanation for this finding could be related to the common pathways between cocaine mechanisms of action and psychosis neurobiology. Cocaine is believed to produce psychotic symptoms by increasing cortical and subcortical dopamine levels, and it is possible to identify an increased synaptic dopamine level both in the cocaine effects and in the positive psychotic symptoms (37), but this topic needs to be evaluated in future studies. This idea is consistent with Cubells et al. who analysed and identified the association between a haplotype at the DBH locus, with low plasma dopamine B-hydroxylase activity in patients with cocaineinduced paranoia (38).

The high frequency of CIP in cocaine-dependent patients gains importance because it involves potential risks for the patients and others. Lapworth et al. identified that both impulsivity and positive psychotic symptoms contribute independently to hostility in methamphetamine users (20). Nevertheless, their effects are amplified when they occur conjointly. They suggest that antisocial behaviours can be triggered by a dangerous perception of the environment, and the impulsivity produced by drug effects. If we assume that this situation can be similar in cocaine users, it is consistent to find more ASPD in patients with CIP, understanding that antisocial behaviours are influenced by an interaction of factors, such as drugs effect on the individual, social context and personality traits. ASPD and CIP have previously been proposed to be linked in cocaine-dependent patients by Tang et al. (7), but in their work did not remain 
statistically associated after Bonferroni corrections. However, in our sample the relationship remained significantly associated. The association of ASPD with CIP suggests that there may be some common vulnerability factors that contribute to both cocaine-induced psychosis and aggressive behaviours (13). It can be based on a dysfunction in the dopaminergic receptors $(6,39-41)$. On the other hand anti-social individuals may be more likely to place themselves in dangerous or anxiety-provoking situations, leading to greater paranoia and visual and auditory hallucinations as well as be more likely to be cannabis dependent as our results show. However, these hypotheses should be studied more in depth.

The high prevalence of cannabis use in primary cocaine-users is known to be around50$70 \%(42,43)$, or cocaine-dependent patients (35.4\%) (13). A strong association between heavy cannabis use and the development of schizophrenia-spectrum psychoses has been described (44, 45). According to Kuepper et al. (46) cannabis is a risk factor for development of incident psychotic symptoms and might increase the risk for psychotic disorders by impacting on the persistence of symptoms. Nevertheless, previous works failed to associate the risk for CIP with lifetime cannabis use (12)or cannabis dependence (13). However we found that patients with CIP had significantly higher rates of cannabis dependence history than those without CIP. Kalayasiri et al. reported an earlier onset of cannabis use in patients with CIP than those without (12). Therefore, we conclude that high cannabis use could be related to CIP; understood as two situations, either an early-onset of use, or the development of cannabis dependence. It is possible that, there are common mechanisms within this association for the development of psychotic symptoms, such as neurobiological pathways that increase the risk of CIP. In the same study, the catechol-O-methyl-transferase (COMT) gene was studied but no interaction was found with early cannabis onset (12).

As limitations of the study, the self-reporting nature of the data must be considered. We evaluated cocaine-dependent patients who were seeking treatment and therefore, these results cannot be generalized to other cocaine-user populations. Cocaine amount used in consumption episodes with psychotic symptoms was not evaluated, for that reason the dose-effect relationship cannot be studied. We can only associate CIP with higher consumption at treatment onset. Another limitation is that symptom severity was not controlled, and our patients were not able to refer symptoms duration and intervention 
needed.

As strengths of the study, we believe that the multivariate analysis including consumption pattern variables and personality disorders is noteworthy. We offered a new model integrating previous knowledge: amount of cocaine consumption, presence of ASPD and cannabis lifetime dependence had a proper sensitivity and specificity to predict the presence of CIP. Furthermore, most previous studies have been performed with American population samples. This study has been carried out in Europe and could be considered relevant, due to the different consumption patterns present in this region, e.g. crack cocaine consumption is not still widespread in Europe (47).

Finally, we consider that professionals who work with cocaine dependent-patients should incorporate these considerations into an integral approach. As CIP is very common in this population, clinicians should be especially attentive and explore it in patients who consume high quantities of cocaine, diagnosed of Antisocial Personality Disorder and/or cannabis dependence history. Identifying these types of symptoms can be useful to minimize the presence and risks during psychotic states.

\section{Acknowledgements}

We are grateful for the support of a Subdirecció General de Drogodependències (Department of Health. Generalitat de Catalunya) grant. Also we are grateful to our research team for their support, particularly Nieves Martínez-Luna (Psychiatrist), Rebeca Ortega (Nurse), Susana Gómez-Baeza, Meritxell Artiaga, Sira Díaz-Morán, and Marina Comín (Psychologists).

\section{Conflict of interest}

The authors declare having no conflict of interest related to the work. 


\section{References}

1. European Monitoring Centre for Drugs and Drug Addiction. 2010 Annual report on the state of the drugs problem in Europe. Lisbon 2010.

2. Kessler RC, Nelson CB, McGonagle KA, Edlund MJ, Frank RG, Leaf PJ. The epidemiology of co-occurring addictive and mental disorders: implications for prevention and service utilization. Am J Orthopsychiatry. 1996;66(1):17-31.

3. Kessler RC, Chiu WT, Demler O, Walters EE. Prevalence, Severity, and Comorbidity of 12-Month DSM-IV Disorders in the National Comorbidity Survey Replication. Arch Gen Psychiatry. 2005 June 1, 2005;62(6):617-27.

4. Satel SL, Edell WS. Cocaine-induced paranoia and psychosis proneness. Am J Psychiatry. 1991;148(12):1708-11.

5. Roncero C, Ramos JA, Collazos F, Casas M. Complicaciones psicóticas del consumo de cocaína. Adicciones. 2001;13:179-89.

6. Cubells JF, Feinn R, Pearson D, Burda J, Tang Y, Farrer LA, et al. Rating the severity and character of transient cocaine-induced delusions and hallucinations with a new instrument, the Scale for Assessment of Positive Symptoms for Cocaine-Induced Psychosis (SAPS-CIP). Drug Alcohol Depend. 2005;80(1):23-33.

7. Tang YL, Kranzler HR, Gelernter J, Farrer LA, Cubells JF. Comorbid psychiatric diagnoses and their association with cocaine-induced psychosis in cocainedependent subjects. Am J Addict. 2007;16(5):343-51.

8. Mahoney JJ, 3rd, Kalechstein AD, De La Garza R, 2nd, Newton TF. Presence and persistence of psychotic symptoms in cocaine- versus methamphetamine-dependent participants. Am J Addict. 2008;17(2):83-98.

9. Mathias S, Lubman DI, Hides L. Substance-induced psychosis: a diagnostic conundrum. The Journal of clinical psychiatry. 2008;69(3):358-67.

10. Kranzler HR, Satel S, Apter A. Personality disorders and associated features in cocaine-dependent inpatients. Compr Psychiatry. 1994;35(5):335-40.

11. Smith MJ, Thirthalli J, Abdallah AB, Murray RM, Cottler LB. Prevalence of psychotic symptoms in substance users: a comparison across substances. Compr Psychiatry. 2009 May-Jun;50(3):245-50. 
12. Kalayasiri R, Gelernter J, Farrer L, Weiss R, Brady K, Gueorguieva R, et al. Adolescent cannabis use increases risk for cocaine-induced paranoia. Drug Alcohol Depend. 2010;107(2-3):196-201.

13. Tang YL, Kranzler HR, Gelernter J, Farrer LA, Pearson D, Cubells JF. Transient cocaine-associated behavioral symptoms rated with a new instrument, the scale for assessment of positive symptoms for cocaine-induced psychosis (SAPS-CIP). Am J Addict. 2009;18(5):339-45.

14. Floyd AG, Boutros NN, Struve FA, Wolf E, Oliwa GM. Risk factors for experiencing psychosis during cocaine use: a preliminary report. J Psychiatr Res. 2006;40(2):178-82.

15. Mooney M, Sofuoglu M, Dudish-Poulsen S, Hatsukami DK. Preliminary observations of paranoia in a human laboratory study of cocaine. Addict Behav. 2006;31(7):1245-51.

16. Kalayasiri R, Kranzler HR, Weiss R, Brady K, Gueorguieva R, Panhuysen C, et al. Risk factors for cocaine-induced paranoia in cocaine-dependent sibling pairs. Drug Alcohol Depend. 2006;84(1):77-84.

17. Kalayasiri R, Sughondhabirom A, Gueorguieva R, Coric V, Lynch WJ, Morgan PT, et al. Self-reported paranoia during laboratory "binge" cocaine self-administration in humans. Pharmacology, biochemistry, and behavior. 2006;83(2):249-56.

18. Bartlett E, Hallin A, Chapman B, Angrist B. Selective sensitization to the psychosis-inducing effects of cocaine: a possible marker for addiction relapse vulnerability? Neuropsychopharmacology. 1997;16(1):77-82.

19. Reid MS, Ciplet D, O'Leary S, Branchey M, Buydens-Branchey L, Angrist B. Sensitization to the psychosis-inducing effects of cocaine compared with measures of cocaine craving and cue reactivity. Am J Addict. 2004;13(3):305-15.

20. Lapworth K, Dawe S, Davis P, Kavanagh D, Young R, Saunders J. Impulsivity and positive psychotic symptoms influence hostility in methamphetamine users. Addict Behav. 2009;34(4):380-5.

21. Östlund A, Hensing G, Sundh V, Spak F. Changes in some personality traits after recovery from alcohol dependence/abuse, anxiety and depression-Results of a 5year follow-up in a general population sample of women. Nord J Psychiatry. 2007;61(4):279-87. 
22. de Groot MH, Franken IHA, van der Meer CW, Hendriks VM. Stability and change in dimensional ratings of personality disorders in drug abuse patients during treatment. J Subst Abuse Treat. 2003;24(2):115-20.

23. Frances RJ, Miller S, Mack AH, editors. Clinical Textbook of Addictive Disorders: Third Edition. New York: The Guilford Press; 2005.

24. Swendsen J, Ben-Zeev D, Granholm E. Real-Time Electronic Ambulatory Monitoring of Substance Use and Symptom Expression in Schizophrenia. Am J Psychiatry. 2011 February 1, 2011;168(2):202-9.

25. Bobes J, Bascarán M, Bobes T, Carballo J, Díaz E, Flórez G, et al. Valoración de la gravedad de la adicción: Aplicación a la gestión y monitorización de los tratamientos. Social MdSyP, editor. Madrid: 2007.

26. Kokkevi A, Stefanis C. Drug abuse and psychiatric comorbidity. Compr Psychiatry. 1995;36(5):329-37.

27. McLellan AT, Kushner H, Metzger D, Peters R, Smith I, Grissom G, et al. The Fifth Edition of the Addiction Severity Index. J Subst Abuse Treat. 1992;9(3):199-213.

28. First MB, Spitzer RL, Gibbon M, Williams JB. Structured Clinical Interview for the DSM-IV Axis I Disorders, Research Version, Patient Edition. (SCID-I/P) New York: Biometrics Research, New York State Psychiatric Institute; 1996.

29. Williams JB, Gibbon M, First MB, Spitzer RL, Davies M, Borus J, et al. The Structured Clinical Interview for DSM-III-R (SCID). II. Multisite test-retest reliability. Arch Gen Psychiatry. 1992 Aug;49(8):630-6.

30. First MB, Gibbon M, Spitzer RL, Williams JB, Benjamin LS, 1997. Structured Clinical Interview for DSM-IV Axis II Personality Disorders, (SCID-II). Washington, D.C.: American Psychiatric Press, Inc.; 1997.

31. Villar Garcia M, Perez Prieto JF, Hernandez Viadel M, Renovell Farre M. Preparation of a SCID-II-based diagnostic tool for personality disorders. Spanish version. Translation and adaption. Actas Lusoespanolas De Neurologia Psiquiatria Y Ciencias Afines. 1995;23(4):178.

32. Volkow ND, Wang GJ, Fischman MW, Foltin R, Fowler JS, Franceschi D, et al. Effects of route of administration on cocaine induced dopamine transporter blockade in the human brain. Life Sci. 2000;67(12):1507-15.

33. Jeffcoat AR, Perez-Reyes M, Hill JM, Sadler BM, Cook CE. Cocaine disposition in humans after intravenous injection, nasal insufflation (snorting), or smoking. Drug Metab Dispos. 1989 March 1, 1989;17(2):153-9. 
34. Fergusson DM, Horwood LJ, Ridder EM. Tests of causal linkages between cannabis use and psychotic symptoms. Addiction. 2005;100(3):354-66.

35. Hall W. The mental health risks of adolescent cannabis use. PLoS Med. 2006;3(2):e39.

36. Brousse G, Vorspan F, Ksouda K, Bloch V, Peoc'h K, Laplanche JL, et al. Could the inter-individual variability in cocaine-induced psychotic effects influence the development of cocaine addiction?: Towards a new pharmacogenetic approach to addictions. Med Hypotheses. 2010;75(6):600-4.

37. Volkow ND. The Addicted Brain: Why Such Poor Decisions? NIDA Notes [serial on the Internet]. 2003; 18(4).

38. Cubells JF, Kranzler HR, McCance-Katz E, Anderson GM, Malison RT, Price LH, et al. A haplotype at the DBH locus, associated with low plasma dopamine betahydroxylase activity, also associates with cocaine-induced paranoia. Mol Psychiatry. 2000;5(1):56-63.

39. Alia-Klein N, Goldstein RZ, Kriplani A, Logan J, Tomasi D, Williams B, et al. Brain monoamine oxidase A activity predicts trait aggression. $\mathrm{J}$ Neurosci. 2008;28(19):5099-104.

40. Mendes DD, Mari Jde J, Singer M, Barros GM, Mello AF. Study review of biological, social and environmental factors associated with aggressive behavior. Rev Bras Psiquiatr. 2009;31 (Suppl 2):77-85.

41. Kalayasiri R, Sughondhabirom A, Gueorguieva R, Coric V, Lynch WJ, Lappalainen J, et al. Dopamine beta-hydroxylase gene (DbetaH) -1021C-->T influences self-reported paranoia during cocaine self-administration. Biol Psychiatry. 2007;61(11):1310-3.

42. Miller NS, Klahr AL, Gold MS, Sweeney K, Cocores JA. The prevalence of marijuana (cannabis) use and dependence in cocaine dependence. N Y State J Med. 1990 Oct;90(10):491-2.

43. Aharonovich E, Hasin DS, Brooks AC, Liu X, Bisaga A, Nunes EV. Cognitive deficits predict low treatment retention in cocaine dependent patients. Drug Alcohol Depend. 2006;81(3):313-22.

44. Moore THM, Zammit S, Lingford-Hughes A, Barnes TRE, Jones PB, Burke M, et al. Cannabis use and risk of psychotic or affective mental health outcomes: a systematic review. The Lancet. 2007;370(9584):319-28. 
45. Roncero C, Collazos F, Valero S, Casas M. [Cannabis consumption and development of psychosis: state of the art]. Actas Esp Psiquiatr. 2007 MayJun;35(3):182-9.

46. Kuepper R, van Os J, Lieb R, Wittchen H-U, Höfler M, Henquet C. Continued cannabis use and risk of incidence and persistence of psychotic symptoms: 10 year follow-up cohort study. BMJ. 2011;342.

47. European Monitoring Centre for Drugs and Drug Addiction. 2009 Annual report on the state of the drugs problem in Europe. Lisbon2009. 